\title{
Modelling-through-reaction: its nature, implementation and potential
}

\author{
Andrew K. Shenton
}

\begin{abstract}
Rooted in modern, person-oriented perspectives within user studies, modellingthrough-reaction is an investigative technique that has been developed by the author over several years with the aim of uniting the often disparate worlds of research and the information professional. The approach results in the creation of principles that represent what the participants believe to be the ideal features of the information entity forming the subject of the research. In sum, these statements constitute a specification that should inform future development of the entity and provide criteria for evaluation. Drawing on a range of sources, this paper explores the early development of modelling-through-reaction and discusses its key characteristics, giving particular emphasis to its flexibility and suitability for use by the information professional, whilst still acknowledging the challenges inherent in its application.
\end{abstract}

\section{Introduction}

Modelling-through-reaction is a research approach that owes its origins to the user studies agenda which has been prevalent in library and information science for many years. In an influential and much-cited paper, Dervin and Nilan (1986) were among the first commentators to detect a paradigm shift away from a systemsoriented approach focusing on external behaviour for exploring information needs and uses towards one based on the internal cognitions of individuals. Writing at the beginning of the twenty-first century, Todd (2003) has gone so far as to suggest that this trend and others identified by the authors in their paper have "guided research and scholarly activity for the last 15 years" (p. 28). Shenton's modelling-through-reaction approach can be considered a product of this more person-centred perspective, incorporating the use of qualitative methods to explore the attitudes and behaviour of users in their own language and in relation to their own concerns.

\section{Andrew Shenton}

Andrew Shenton is a former Lecturer in the Division of Information and Communication Studies at Northumbria University.

E-mail: ashenton1@hotmail.com 
Part of the inspiration for modelling-through-reaction came from the need to bridge the gap between research and information practitioners. Undoubtedly, much of the published research in LIS holds little appeal for information professionals. As Eve and Schenk (2007) appreciate, very often for these people, research may seem irrelevant to their real areas of interest, and the contents of academic journals look "dry and impenetrable" to them (p. 22). This is despite the fact noted by MacDonald (2007) that, with the backgrounds of many librarians lying in the humanities rather than mathematics or the "hard" sciences, they may well feel more comfortable with qualitative work, and the shift in this direction, at least insofar as user studies is concerned, should favour them. In recent years, much of Shenton's work has concentrated on uniting the domains of research and practice. With Jackson, he has explored the interaction between the study of information behaviour and the teaching of information literacy by information professionals (Shenton and Jackson, 2007), alerted practitioners to the journals in which research on information behaviour is frequently found so that they may stay up-to-date with the latest work (Shenton, in press c) and encouraged researchers to publish their projects in professional periodicals, as well as scholarly journals (Shenton, in press b).

The modelling-through-reaction approach seeks to reduce further the gap between researchers and practitioners by offering an investigative method that is easy to implement and which focuses on matters of genuine interest to information workers and the users they serve. In a passionate recent article, Clarke (2009) asserts, "If we as librarians want to heighten our profile we need to bond with our users and provide the type of service they need and demand". Although Clarke's piece was written several years after work began on the modelling-throughreaction method and her comments are made specifically in relation to her own experience as an information professional, rather than a particular research agenda, her attitude encapsulates in the most fundamental terms the rationale for the development of the modelling-through-reaction approach.

\section{Early development}

Essentially, modelling-through-reaction explores the views of both users and nonusers of an information entity, such as an organisation, service, resource or product, so as to model what, in their eyes, would form its ideal characteristics. The technique has evolved in stages over the course of the last three years. An embryonic form was pioneered for a project designed to reveal the attitudes of pupils to their library in a high school in northern England (Shenton, 2008a). The brand of modelling-through-reaction employed in that study, however, was devoted exclusively to the negative responses of the participants - it concentrated entirely on how they thought the existing library could be improved. Ultimately, the researcher was able to formulate from the data collected six key principles that should be considered by managers for the development of the library and which may be adopted as criteria for the evaluation of that library in the future. On the basis of the ideas of pupil participants, the ideal school library was regarded as one: 
a) that offers abundant, useful and stimulating stock;

b) where the organisation of books is helpful and intuitive to use;

c) in which books can be borrowed at any time of the day;

d) whose ambience is welcoming and appropriate for youngsters wanting to use the area for different reasons;

e) where staff can empathise with young people;

f) that is accommodated in a dedicated space.

The idea of pupil feedback providing an input into the process of assessing a school library is by no means novel, of course. Indeed, Barrett and Douglas (2004) note in general terms the role of evidence from users and non-users in "evaluating the extent to which the library impacts upon the school" (p. 72) but the notion of using youngsters' ideas to formulate specific criteria that reflect their own priorities is rather more unusual.

Whilst the approach employed in the project elicited data that proved more than adequate for the satisfying of the study aims and objectives, the use of "negative data" in the way that was applied would not meet with universal approval. In this respect, the pertinent arguments of Donald Urquhart, the renowned innovator in document delivery services and who may be considered to take a dissenting line, should at least be acknowledged. In an influential treatise on the nature of librarianship, Urquhart (1981) is sceptical of research addressing what "users think they want, or what they think they would do in some hypothetical situation" and dismisses data relating to these areas as "not objective" (p. 17). Nevertheless, it must be recognised that Urquhart's stance is symptomatic of the era in which it was taken, before the widespread acceptance of qualitative methods. Urquhart is keen that researching librarians adhere to the stipulations of scientific method in a quest for objectivity but modelling-through-reaction and indeed much of today's wider user studies agenda are less concerned with objectivity than with gaining an appreciation of the subjective worlds of information users. Thus, to assess in terms of objectivity a project that emphasises internal cognitions is to apply an inappropriate criterion for its evaluation.

A second project employing the modelling-through-reaction approach with young people broadened the line of questioning, here in relation to the Teletext information service. As well as asking, "If you don't use Teletext, why is this?", the researcher incorporated a "positive" element, probing the reasons why pupils who used Teletext did so, and what benefits they felt the resource offered. The inspiration behind this strand came from work on "willingness to return" by Turner and Durrance (2005), who have suggested that the success, from the client's perspective, of the reference interview in a library can be measured by ascertaining the willingness of the individual to return to the same member of staff on a future occasion. Extending this theme, Shenton (2008b) has recommended that, by employing focus groups or individual interviews, the researcher can uncover what it is about the library that makes youngsters go back to it with a view to gaining insight into "the difference that the library makes to their quality of life". The underlying principle was then transferred to Teletext 
use. In a previous article dealing with modelling-through-reaction, Shenton (in press a) explains how, in such situations, the aim of the double-pronged strategy is to prepare principles emphasising the desirable characteristics of the resource and converting perceived weaknesses into positive statements in order to produce an overall specification embodying the requirements of users.

The "Teletext" study was intended as the first stage within an ambitious project that would also explore pupil attitudes to the Internet, CD-ROM and the school's intranet, and use the cumulated data to model the ideal electronic information resource. The first phase was much less successful than anticipated, however, and the failure revealed a key shortcoming in the modelling-through-reaction method - the participants must have at least some knowledge of the entity in question so that an informed opinion can be expressed. The project fell short of expectations because very few of those sampled knew sufficient about Teletext. In the light of the fact that an earlier study at the same school (Shenton, 2007c) had shown the use of Teletext to be minimal among the teenagers, this possibility should probably have been recognised from the outset. A major difference between the "willingness to return" approach put forward by Shenton (2008b) and the line taken in the "Teletext" investigation was that, in the latter, no attempt was made to recruit enthusiastic users. Still, the problem of unfamiliarity should not be assumed to imply that non-users cannot make a significant contribution to research based on the modelling-through-reaction approach. On the contrary, in the previous work on attitudes to the school library, useful data were elicited from some twenty-two pupils who indicated that they "never" used the facility. Rather than being ignorant of the library, these youngsters were well aware of it and were very clear in their justifications for ignoring the facility. Although they may have lacked an understanding of its more detailed characteristics, their lively opinions on how the library could be made more attractive to them could form a helpful input into the design of an improved service. More broadly, drawing on the ideas of users and non-users in concert can provide a richness in the data collected within a project that would be absent if only the former were sampled. The main challenge may well lie in finding the most effective method of recruiting as participants non-users, who may be tempted to dismiss research concentrating on something that they do not exploit as "nothing to do with me". The problem of involving non-users has for many years perplexed researchers undertaking projects into the use of libraries. One of the most imaginative solutions was reported by Murray (1985) in the mid 1980s. Acknowledging the need to approach youngsters beyond, as well as within, the library, she recounts how the questionnaire prepared was distributed in environments as diverse as three shopping malls, a pinball arcade and a community swimming pool.

\section{The versatility of modelling-through-reaction}

A significant strength of the modelling-through-reaction approach lies in its flexibility in terms of both the entities that may be scrutinised and the nature of the participants from whom data may be collected. Shenton (in press a) has, in the past, noted its particular suitability with regard to young people, as it allows them to discuss their attitudes to a concrete matter. The task of devising the abstract principles that form the research outcomes falls entirely on the shoulders of the 
researcher. The language in which the questions are framed can easily be made suitable to the age of the child. When working with young children, for example, the foci may be as straightforward as why those who do use the school library go to it, what they like about it and what they would want to be different about the library, whilst non-users may be asked why they ignore it and what would attract them if changes were made. There is no reason, of course, why modellingthrough-reaction should be limited to the LIS field. It could, for example, be extended to address learning programmes and courses in Further and Higher Education.

Although early studies using the modelling-through-reaction approach have been of the one-off variety, sampling youngsters in a given school at a certain time, if the researcher is attempting to develop principles for an ideal school library that have a measure of constancy over time, it may be appropriate to take a longitudinal perspective, repeating the study after, say, a five-year period has elapsed, when all the pupils taking part in the original project will have moved on and general principles for an attractive library in the eyes of users can be constructed from the totality of the data in both studies. In defining his "principles of librarianship", Urquhart (1981), however, attaches great importance to their immutability. He writes, "they should not be changed by the passage of time or technological developments" (p. 10). Anyone subscribing to this argument may expect that if principles were to be evolved from two different studies separated by several years, there would be few differences between them and thus there is very little need for a longitudinal element.

Even where the focus of the research is, for example, the ideal public library, it is possible that the particular organisation under scrutiny may vary from one participant to another. A study may initially concentrate, for example, on a named public library but, in a secondary phase, the insights that have already emerged may be explored with reference to users and non-users of other libraries in the area. Such research may seem to run the risk of failing to give sufficient attention to the various contextual factors that may affect users of different libraries but confirmatory work of this kind is not uncommon in LIS. Friel (1995), for instance, has explored the suitability of Kuhlthau's Information Search Process model specifically in relation to low-achieving students, and Kuhlthau herself has investigated the appropriateness of her original model to different groups of library user (Kuhlthau et al, 1990). Similarly, Ellis developed his first model of information-seeking with social scientists (Ellis, 1989), and then compared the patterns he had identified with those pertaining to research physicists and chemists (Ellis, Cox and Hall, 1993) and, later, industrial scientists (Ellis and Haugan, 1997). More recently, after delineating the various ways in which the word, "information", was understood by school pupils in north-east England (Shenton, 2002), Shenton has undertaken collaborative work with Nesset and Hayter to ascertain the relevance of his original set of constructs to Canadian elementary school pupils (Shenton, Nesset and Hayter, 2008).

The application of a modelling-through-reaction strategy can lead to a range of insights into the information needs/wants that participants either actually meet or would like to satisfy using the entity in question. Illumination of the second kind may lead to an understanding of what commentators such as Faibisoff and Ely 
(1976, p. 3), Cronin (1981, p. 40) and Nicholas (2000, p. 23) term "unexpressed" needs - needs of which the individual may be aware but has not acted upon. There is a clear overlap between modelling-through-reaction and the well established help chain strategy for researching information needs. Shenton (2009) reports how, in the latter, the way in which a particular library or resource centre, for example, has assisted the user in fulfilling a certain information need is investigated, with attention initially directed to the individual's interaction with the organisation, rather than on the need itself. In view of the great divisions of opinion with the LIS community surrounding the differences in nature between information needs and information wants, it would be unwise of the researcher to call on participants to make any such distinctions themselves. This means, however, that, in looking to make sense of the data at a later stage, the analyst may be faced with the challenging task of creating such separations unaided, although by no means all commentators feel it necessary even to make a distinction. In her own research, Gratch (1978) subsumes information wants within the construct of information needs, and Reuter's (2007) belief that such needs include "gratifications" (p. 139) would appear to blur the categories. An acclaimed work by Williams (1965) draws attention to another situation that highlights the problems inherent in the needs/wants separation. He recognises how, despite its apparent frivolity, the reading of what he terms "ephemeral writing" can meet an important need in times of "illness, tension, disturbing growth as in adolescence, and simple fatigue after work" (p. 193).

\section{Caveats}

Modelling-through-reaction is undoubtedly ill suited for the designing from scratch of entities that are radically new, since it takes as its starting point the perspectives of participants on something already in place. It is much better equipped for providing a means of redeveloping or re-orientating an existing entity.

It must be understood, too, that what is learnt from a modelling-through-reaction study should provide only one input into a future course of action pursued by senior managers. In an old but still pertinent article, Bradshaw (1972) investigates the concept of "normative need", which he describes as "what the expert or professional, administrator or social scientist defines as need in any given situation" (p. 640). The phenomenon of "dormant need" identified by Nicholas (2000) and also discussed, using different terms and with reference to a diversity of scenarios, by commentators such as Dervin (1976), Faibisoff and Ely (1976), Derr (1983), Cronin (1981), Green (1990), Nicholas (2000) and Shenton (2007b), can be considered a justification for responding to normative needs, since users themselves may not necessarily be aware of all their needs. It is instructive to note that Walter's oft-cited study of children's information needs (Walter, 1994) is based entirely on a normative perspective. Although the extent to which the manager of a library or information unit must strike a balance between catering for the needs/wants of participants and meeting the normative needs stipulated by an external expert may appear to be a key challenge, early work using the modelling-through-reaction approach suggests the correspondence of the two may be closer than one might expect. Each of the six principles formulated in the 
school library project covered earlier may be understood, to either a greater or lesser degree, in terms of one or more of the four problematic areas for school libraries noted by Phil Jarrett, HMI subject Advisor for English (Jarrett, 2006). The appropriate relationships are shown in Table 1.

\begin{tabular}{|l|l|}
\hline Pupil principles for the ideal school library & $\begin{array}{l}\text { Jarrett's } \\
\text { problematic } \\
\text { areas }\end{array}$ \\
\hline It offers abundant, useful and stimulating stock & $\begin{array}{l}\text { Funding; } \\
\text { resources }\end{array}$ \\
\hline The organisation of books is helpful and intuitive to use & $\begin{array}{l}\text { Resources [and } \\
\text { their } \\
\text { management]; } \\
\text { staffing }\end{array}$ \\
\hline Books can be borrowed at any time of the day & Staffing \\
\hline $\begin{array}{l}\text { The ambience is welcoming and appropriate for youngsters } \\
\text { wanting to use the area for different reasons }\end{array}$ & $\begin{array}{l}\text { Funding; } \\
\text { accommodation; } \\
\text { resources }\end{array}$ \\
\hline Staff can empathise with young people & Staffing \\
\hline It is accommodated in a dedicated space & Accommodation \\
\hline
\end{tabular}

Table 1: Associations between pupil principles resulting from modellingthrough-reaction and Jarrett's problematic areas

When the pupils' ideas in the school library study are compared with those of the young people who participated in research conducted by The Reading Agency (2004), clear areas of consensus can be recognised here too. In particular, those youngsters also spoke of the importance of a wide "choice of relevant reading material", opening hours that were convenient, a "welcoming atmosphere" and a "separate space" (p. 22).

The possibility of tensions emerging between the ideas of study participants and those of other interested parties is an obvious potential problem. The researcher might expect pupils to feel that computers in the school library should be available for games, private e-mailing and the pursuit of information in response to personal interests, whilst senior managers within the school may be more concerned with ensuring that the machines are employed for educational tasks and supporting the curriculum. Moreover, conflicting patterns may also arise within the data themselves if youngsters' perspectives are sufficiently at variance with one another. A significant contrast in the data elicited for the school library research project was that, whereas some participants believed that the library should offer a quiet place for study, others maintained it should be a more social environment, where they could meet with friends (Shenton, 2007a). Often, however, the task of uniting such seemingly irreconcilable viewpoints can be achieved by formulating an especially broad principle. It may, for example, stress that the library or computers within it should serve a wide variety of purposes. 
Where what is desired by participants runs diametrically opposed to the policy of senior managers, it may be impossible to accommodate the former to a significant degree and, in these circumstances, any attempt that has been made to represent the modelling-through-reaction research as part of a genuinely consultative process may be perceived to be a sham. If the desires of users are simply "moderated", rather than rejected outright, the revised stipulations may form a particular kind of Taylor's (1968) "compromised" need (p. 182). In this context, Taylor explains how an individual's information need may be recast in accordance with the constraints that are in place. In the same way, the needs and wants of those participating in modelling-through-reaction research may well be "compromised" by senior managers in order that they may conform to existing policies, the aims and objectives of the organisation and the school's wider educational mission, as well as what is practical.

\section{Modes of data collection and analysis}

Early work featuring the modelling-through-reaction approach has involved the use of questionnaires, although much richer data can, of course, be collected via individual interviews and focus groups. Indeed, as the author has noted in a previous article (Shenton, 2006), qualitative researchers may be wary of using questionnaires since respondents merely react to "generic questions presented to all participants and there is no scope for the investigator to pursue, through more personally oriented follow-up prompts, the individual issues raised" (p. 2).

Nevertheless, the use of a single, generic set of questions for all respondents in a particular study, even if different people have used different libraries or different reference books, is attractive in that it reduces preparatory work for the researcher and facilitates comparability of data but the questions must be phrased with care so that they are equally appropriate to everyone. Regardless of whether one-to-one interviews, focus groups or questionnaires are employed, the data collected should be categorised and coded on the basis of the inherent themes and the ultimate outcome will take the form of a set of general principles for the "ideal" as seen through the eyes of users. For inexperienced researchers, the categorising and coding process may form the most challenging aspect of the project.

\section{Conclusions}

Modelling-through-reaction is a highly flexible research approach that may be implemented in a design that involves focus groups, one-to-one interviews or questionnaires, with "positive" and "negative" data solicited from users and nonusers. It is easy to apply whether the participants are young or old. The entities that may be subjected to scrutiny are similarly diverse. In an LIS context, they may include information organisations, services, resources and products. Modelling-through-reaction may also be applied to issues beyond our discipline. The principles that form the research outcomes may be used for both future development and evaluation.

Where modelling-through-reaction is employed in relation to a certain library and the study is undertaken by an information professional employed within the organisation, that person is well placed to understand the pupils' attitudes in terms of the particular characteristics of the organisation, its services and procedures, 
and the nature of the users themselves. In short, the research is not being conducted in a "vacuum". This situation contrasts with work that may aim to identify the characteristics of the ideal reference book, since it may well be that the volumes which form the subject of participants' ideas are located in the users' homes and are never even seen by the information specialist, who is thus poorly placed to understand the participants' attitudes in-context.

For all its attractions, modelling-through-reaction raises a number of important challenges for the researcher, notably how normative perspectives, beyond the attitudes of the participants, will be accommodated within the overall policy making process and how contextual factors outside the realms of the practitionerresearcher's experience and which may affect the data collected can be recognised and acknowledged.

\section{References}

Barrett, L. and Douglas, J. (2004) The CILIP guidelines for secondary school libraries. London: Facet.

Bradshaw, J. (1972) The concept of social need, New Society, 496, 640-643.

Clarke, C. (2009) Time to start shouting at school, Library and Information Gazette, 19 June - 2 July, 4.

Cronin, B. (1981) Assessing user needs, Aslib Proceedings, 33(2), 37-47.

Derr, R.L. (1983) A conceptual analysis of information need, Information Processing and Management, 19(5), 273-278.

Dervin, B. (1976) The everyday information needs of the average citizen: A taxonomy for analysis. In: Kochen, M. and Donohue, J.C. (eds.) Information for the community. Chicago: American Library Association. 19-38.

Dervin, B. and Nilan, M. (1986) Information needs and uses, Annual Review of Information Science and Technology, 21, 3-33.

Ellis, D. (1989) A behavioural approach to information retrieval system design, Journal of Documentation, 45(3), 171-212.

Ellis, D. and Haugan, M. (1997) Modelling the information seeking patterns of engineers and research scientists in an industrial environment, Journal of Documentation, 53(4), 384-403.

Ellis, D., Cox, D. and Hall, K. (1993) A comparison of the information seeking patterns of researchers in the physical and social sciences, Journal of Documentation, 49(4), 356-369.

Eve J. and Schenk N. (2007) Informing and communicating research: Everyone's responsibility, Library and Information Update, 6(6), 22-23.

Faibisoff, S.G. and Ely, D.P. (1976) Information and information needs, Information Reports and Bibliographies, 5(5), 2-16. 
Friel, L. de L. (1995) The information research process with low-achieving freshmen using Kuhlthau's six-stage model and the interventions that facilitate the process. $\mathrm{PhD}$ thesis, University of Massachusetts Lowell.

Gratch, B. (1978) Final report of the Pioneer Library System, LSCA no. 78-19, Central Library young adult project. New York: Rochester Public Library.

Green, A. (1990) What do we mean by user needs? British Journal of Academic Librarianship, 5(2), 65-78.

Jarrett, P. (2006) What makes a good school library? School Libraries in View [online], 22. URL: http://www.cilip.org.uk/NR/rdonlyres/14481A36-2A54-4A7FA6B7-6433B8FDCAD1/0/sliv22b_new.pdf [accessed 11.07.09].

Kuhlthau, C. C., Turock, B. J. and George, M. W. (1990) Validating a model of the search process: A comparison of academic, public and school library users, Library and Information Science Research, 12(1), 5-32.

MacDonald, B.H. (2007) When numbers alone are not enough: Applications of qualitative methodologies, Feliciter, 53(1), 26-29.

Murray, B-K.W. (1985) Regina public library's survey of young adults. In: Gagnon, A. and Gagnon, A. (eds.) Meeting the challenge: Library service to young adults. Ottawa: Canadian Library Association. 55-65.

Nicholas, D. (2000) Assessing information needs: Tools, techniques and concepts for the Internet age. 2nd Ed. London: Aslib.

The Reading Agency (2004) Fulfilling their potential: A national development programme for young people's library services. URL:

http://www.readingagency.org.uk/young/young\%20peopleupload/FPsummaryreport04.pdf [accessed 13.09.09].

Reuter, K. (2007) Children selecting books in a library: Extending models of information behavior to a recreational setting. Saarbrücken: VDM Verlag Dr. Muller.

Shenton, A.K. (2002) The characteristics and development of young people's information universes. $\mathrm{PhD}$ thesis, Northumbria University, Newcastle upon Tyne.

Shenton, A.K. (2006) Squaring the circle: Appreciating the individual in questionnaire-based research, Information Research Watch International, December, 2-3.

Shenton, A.K. (2007a) Attitudes to books and school libraries among teenagers in an English high school, New Review of Children's Literature and Librarianship, 13(1), 31-57.

Shenton, A.K. (2007b) Viewing information needs through a Johari Window, Reference Services Review, 35(3), 487-496.

Shenton, A.K. (2007c) The information-seeking behaviour of teenagers in an English high school, School Librarian, 55(3), 125-127. 
Shenton, A.K. (2008a) What makes an ideal school library? Some lessons from pupil criticism. School Librarian, 56(2), 80-81.

Shenton, A.K. (2008b) Let's give ourselves credit for what we do well, Youth Libraries Group: News [online], Summer. URL:

http://www.cilip.org.uk/specialinterestgroups/bysubject/youth/publications/eylr/N ews-+Summer+2008.htm [accessed 11.07.09].

Shenton, A.K. (2009) "Help chains", information needs and independent learning areas, School Libraries in View [online], 27. URL:

http://www.cilip.org.uk/NR/rdonlyres/18EAC596-F587-46B9-849FBC45BF99E3B7/0/andrewshentonarticle27.pdf [accessed 22.09.09].

Shenton, A.K. (in press a) Modelling-through-reaction: The possibilities for user research, Information Research Watch International.

Shenton, A.K. (in press b) Researchers and information professionals: Reconciling the two parties, Information Research Watch International.

Shenton, A.K. (in press c) Uniting information behaviour research and the information professional: Identifying the key journals, Library Review.

Shenton, A.K. and Jackson, M. (2007) Information literacy teaching and information behaviour, Library and Information Update, 6(4), 42-43.

Shenton, A.K., Nesset, V. and Hayter, S. (2008) Children's conceptualizations of the word "information". Journal of Librarianship and Information Science, 40(3), 151-164.

Taylor, R.S. (1968) Question-negotiation and information seeking in libraries, College and Research Libraries, 29(3), 178-194.

Todd, R. (2003) Adolescents of the Information Age: Patterns of information seeking and use, and implications for information professionals, School Libraries Worldwide, 9(2), 27-46.

Turner, T.C. and Durrance, J.C. (2005) Willingness to return. In: Fisher, K.E., Erdelez, S. and McKechnie, L. (eds.) Theories of information behavior. Medford, New Jersey: Information Today. 382-386.

Urquhart, D. (1981) The principles of librarianship. Leeds: Wood Garth.

Walter, V.A. (1994) The information needs of children, Advances in Librarianship, 18, 111-129.

Williams, R. (1965) The long revolution. Harmondsworth: Pelican. 